\title{
Effects of Symbiodiniaceae Phylotypes in Clades A-E on Progeny Performance of Two Giant Clams (Tridacna squamosa and T. crocea) During Early History Life Stages in the South China Sea
}

OPEN ACCESS

Edited by:

Xiaotong Wang,

Ludong University, China

Reviewed by:

Huaiping Zheng,

Shantou University, China

Khor Waiho,

University of Malaysia

Terengganu, Malaysia

Wai Kuen Ko,

The University of Hong Kong,

Hong Kong

*Correspondence:

Lijuan Long

ljlong@scsio.ac.cn

Ziniu Yu

carlzyu@scsio.ac.cn

†These authors have contributed equally to this work

Specialty section:

This article was submitted to

Aquatic Physiology,

a section of the journal

Frontiers in Marine Science

Received: 26 November 2020

Accepted: 11 January 2021

Published: 02 February 2021

Citation:

Long C, Zhang Y, Li Y, Li J, Zhou Z,

Qin Y, Li X, Ma H, Wei J, Zhou Y,

Noor Z, Long $L$ and $Y u Z$ (2021)

Effects of Symbiodiniaceae

Phylotypes in Clades A-E on Progeny

Performance of Two Giant Clams

(Tridacna squamosa and T. crocea) During Early History Life Stages in the South China Sea.

Front. Mar. Sci. 8:633761. doi: 10.3389/fmars.2021.633761

\begin{abstract}
Chao Long ${ }^{1,2,3,4,5 t}$, Yuehuan Zhang ${ }^{1,2,4,5 t}$, Yunqing Li $^{1,2,3,4,5}$, Jun Li ${ }^{1,2,4,5}$, Zihua Zhou ${ }^{1,2,4,5}$, Yanping Qin ${ }^{1,2,4,5}$, Xingyou $L^{1,2,3,4,5}$, Haitao Ma ${ }^{1,2,4,5}$, Jinkuan Wei ${ }^{1,2,4,5}$, Yinyin Zhou ${ }^{1,2,3,4,5}$, Zohaib Noor ${ }^{1,2,3,4,5}$, Lijuan Long ${ }^{1,2,4,5 *}$ and Ziniu $Y u^{1,2,4,5 *}$

${ }^{1}$ CAS Key Laboratory of Tropical Marine Bio-resources and Ecology, Guangdong Provincial Key Laboratory of Applied Marine Biology, South China Sea Institute of Oceanology, Chinese Academy of Science, Guangzhou, China, ${ }^{2}$ Innovation Academy of South China Sea Ecology and Environmental Engineering, Chinese Academy of Science, Guangzhou, China, ${ }^{3}$ University of Chinese Academy of Sciences, Beijing, China, ${ }^{4}$ Southern Marine Science and Engineering Guangdong Laboratory, Guangzhou, China, ${ }^{5}$ Hainan Provincial Key Laboratory of Tropical Marine Biology Technology, Sanya Institute of Oceanology Chinese Academy of Sciences, Sanya, China
\end{abstract}

Unlike most bivalves, giant clams (tridacnids) harbor symbiotic microalgae (zooxanthellae) in their other fleshy bodies. The effects of mixed populations of zooxanthellae on larval metamorphosis has been reported in several papers, but there have been very few studies on the effects of single zooxanthella species on the establishment of symbiosis in giant clams. In this study, we obtained five pure zooxanthella species (clades A3, B1, C1, D1, E1) from antler coral by molecular identification, and analyzed their effects on the larval metamorphosis and progeny performance of two giant clams, Tridacna squamosa and T. crocea, in the South China Sea. Clam larvae with all five zooxanthella species underwent larval settlement and metamorphosis, and formed the zooxanthellal tubular system. There was some variation in metamorphic rate and time to metamorphosis between clams with different zooxanthella species, but no significant differences in size at metamorphosis. After metamorphosis, larvae with all zooxanthella types continued to develop normally. Mantle color was consistent within clam species and zooxanthella species had no effect on mantle color. However, clam progeny with clade E1 zooxanthellae were smaller than progeny with the other four zooxanthella clades (A3, B1, C1, and D1). Survival rate was over 90\% for all progeny and there were no significant differences in survival between progeny with Symbiodinium clades A-E during the entire culture process. Two-way ANOVA analysis revealed that giant clam species was the main factor influencing progeny growth, with some variation in growth attributable to zooxanthella type. Our results provide new information on both the symbiotic relationship between giant clams and zooxanthellae and the mantle coloration of giant clams, and will be useful in giant clam seed production and aquaculture.

Keywords: giant clams, zooxanthellae, metamorphosis, symbiosis, mantle coloration 


\section{INTRODUCTION}

Zooxanthellae are found in several marine invertebrates, including corals, sea anemones, molluscs and other taxa, and are major producers of primary productivity in tropical and subtropical coral reef ecosystems (Neo et al., 2015). These symbiotic dinoflagellates in the genus Symbiodinium have been the subjects of scientific investigation, especially in the coral reef ecosystem which is in danger of collapse from anthropogenic global climate change in recent decades (Mies, 2019). Traditionally, zooxanthellae were divided into nine types: clades A-I. Recently, Symbiodinium "clades" have been partitioned into multiple genera to better reflect their origins and divergence during their long evolutionary history, as determined by molecular dating (LaJeunesse et al., 2018). Each zooxanthella species may exhibit unique physiological characteristics, and the cladal composition within the host may influence its survival and ability to tolerate environmental changes.

Giant clam species are an important part of coral reefs with great ecological and economic value, and are distributed throughout the tropical Indo-Pacific from the East African coast to the Pitcairn Islands in the eastern Pacific, and from Okinawa in Japan to south of the Great Barrier Reef (GBR) in Australia (bin Othman et al., 2010; Neo et al., 2017). It is well-known that giant clams have a mutualistic relationship with dinoflagellates of the genus Symbiodinium, also known as zooxanthellae (Hirose et al., 2006; Mies, 2019). Zooxanthellae supply nutrients to the giant clam host, and the host provides a suitable living environment for the symbiotic algae (Fitt et al., 1986). Interestingly, giant clams harbor a wide range of zooxanthellae, consisting of diverse phylotypes (clades). Among bivalves, the association with Symbiodinium is unique to Tridacninae and Fraginae (Kirkendale and Paulay, 2017; Rossbach et al., 2020).

In giant clams, zooxanthellae are not vertically transmitted and must be acquired by larvae from external sources. Several studies have been published on the effects of mixed populations of zooxanthellae on the phenotypic traits of giant clam progeny, focusing on the larval to spat stages (Hernawan, 2008; Neo et al., 2015; Mies, 2019). Symbiotic dinoflagellates can provide nutrition and promote growth development in larval and juvenile giant clams (Fitt et al., 1986). Molea and Munro (1994) isolated zooxanthellae from Tridacna gigas, T. maxima, T. crocea, and Hippopus hippopus, supplied them to T. gigas larvae, and found that ingestion of zooxanthellae from different species caused significant differences in progeny growth. Zooxanthellae isolated from giant clams, corals, and anemones have been found to alter larval survival due to the different physiological adaptions of each zooxanthellae species, but all species promote the metamorphosis of giant clam larvae (Kurihara et al., 2012; LaJeunesse et al., 2018). Viable zooxanthella in the fecal pellets of giant clams are photosynthetically competent and infected T. squamosa larvae are able to undergo metamorphosis (Yu et al., 2016; Morishima et al., 2019). The composition of symbiotic algae in juvenile tridacnids has been shown to be able to change over time (BeldaBaillie et al., 1999).

However, there are few reports of the effects of pure zooxanthellae on giant clam performance (Mies, 2019). Mies et al. (2017a) found that three symbiosis-related fatty acids were produced by Symbiodinium types in clades A-F associated with giant clam larvae, which may provide nutrition for larval metamorphosis. Bleaching of giant clam larvae in coral reefs is related to species of zooxanthellae and seawater temperature, with larvae infected with Symbiodinium type A1 having good resistance to high temperatures (Mies et al., 2018). Analysis of the infection of giant clam larvae with Symbiodinium type A1 revealed a symbiosis-specific gene which may be the earliest example of a co-expressed gene in the larval metamorphosis process (Mies et al., 2017b). Therefore, recognizing the diversity, physiology, and ecology of these endosymbionts is paramount for understanding how algal-invertebrate partnerships might respond to adaptive evolution in symbiology.

In this study, the effects of five pure zooxanthellae species (clades A3, B1, C1, D1, and E1) on phenotypic traits (survival, metamorphosis, growth, and mantle color) of two giant clams (T. squamosa and T. crocea) were evaluated over the first year of life in the South China Sea. A detailed understanding of the early life history and process of symbiosis development were developed, and the process of iridocyte formation during the spat rearing phase was described. We also analyzed the relationships between giant clam species and zooxanthella clades using a twoway ANOVA, and demonstrated the process of mantle color development during the early history life stages.

\section{MATERIALS AND METHODS}

\section{Algae Types}

Zooxanthellae were isolated from Acropora tenuis (clade C1) and Galaxea fasciculrris (clade D1) using Huang's method (Huang et al., 2008). Clade A3, B1, and E1 were separated from the seawater. $0.5 \mathrm{~L}$ seawater was obtained from coral reef area, and three zooxanthellae's clades (A3, B1, and E1) were successfully isolated single cell culture. All clades were reared individually in 36 sterile centrifuge tubes $(2 \mathrm{~mL})$ under the following conditions: $23^{\circ} \mathrm{C}, 33$ ppt seawater in a light incubator at the South China Sea Institute of Oceanology, Chinese Academy of Science, Guangzhou city. After 1 month, we analyzed these living proliferous zooxanthellae with molecular identification (16S rDNA and mitochondrial COI) and found that they belonged to five clades: A3, B1, C1, D1, and E1. These five zooxanthellae clades were then separated by clade into five glass triangular bottles $(100 \mathrm{~mL})$ and reared in the same conditions. Thus, we obtained five types of pure symbiotic algae.

\section{Larvae Source}

T. squamosa and T. crocea were induced to spawn separately at the Hainan Tropical Marine Life Experimental Station at the Chinese Academy of Sciences using the method previously described (Zhang et al., 2016, 2020a,b). After 36 h of fertilization, D-larvae from each clam species were collected on a $70-\mu \mathrm{m}$ sieve and reared separately in two 1000-L tanks filled with $2 \mu \mathrm{m}$ filtered seawater. The initial larval density was adjusted to 2 larvae $/ \mathrm{mL}$ and was maintained at this level by controlling the water volume. The larvae were fed on Isochrysis galbana for the first 5 days at a density of 3000 cells/mL per day. Salinity 33 ppt, pH 8.0-8.3, and 


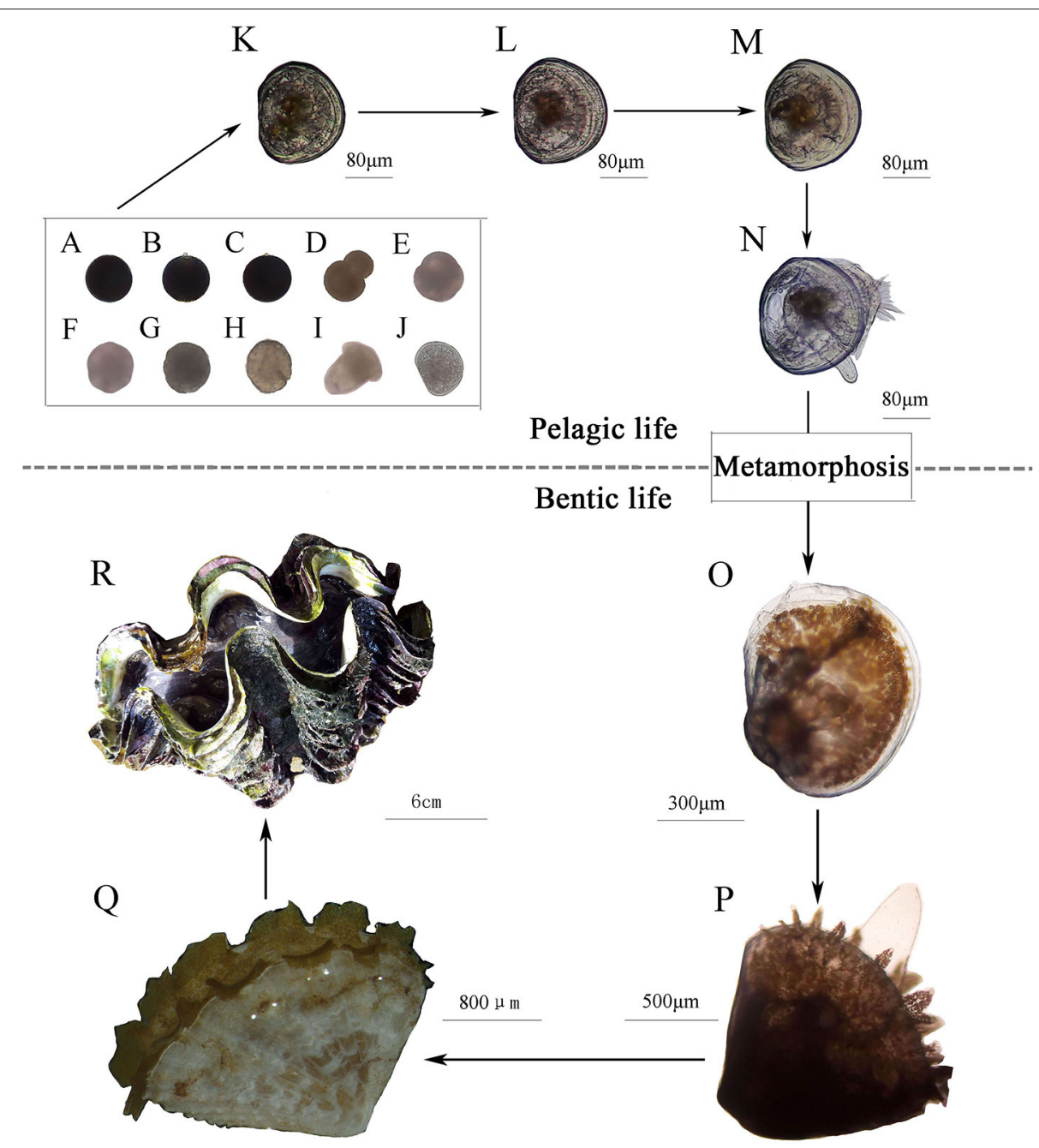

FIGURE 1 | Life cycle of giant clams (T. squamosa). (A) Fertilized egg; (B) First polar body; (C) Second polar body; (D) Two cells; (E) Four cells; (F) Eight cells; (G) Mulberry; (H) Blastocyst; (I) Trochophore; (J) D larva; (K) Early umbo-larva; (L) Middle umbo-larva; (M) Late umbo-larva; (N) Pediveliger; (O) Newly-formed spat; (P) Spat; (Q) Youth; (R) Adult.

temperature range $28.0-29.0^{\circ} \mathrm{C}$ were maintained throughout the embryonic and larval development stages (Figures 1A-N).

\section{Experimental Design}

Six-day-old larvae of two giant clam species (Figure 1N) were concentrated and separated into 10 groups (five groups per clam species). From day 6 to day 9, they were then severally soaked in $1 \mathrm{~L}$ zooxanthellae solution of clade A3, B1, C1, D1, or E1 daily for $2 \mathrm{~h}$ at a density of $10^{3} / \mathrm{ml}$. Then, larvae were transferred to $50 \mathrm{~L}$ plastic buckets at a density of $0.5 \mathrm{ind} . / \mathrm{mL}$, with each group replicated three times. That is, five zooxanthellae clades from 30 plastic buckets were used for this experiment (Table 1). To avoid wild zooxanthellae contamination, all experimental seawater was filtered through $2-\mu \mathrm{m}$ mesh. Larval rearing buckets were provided with gentle aeration and exposed to natural sunlight that was reduced using a transparent polycarbonate roof sheeting and 50\% light transmittance shade-cloth. The daily-maximum photosynthetically active radiation (PAR) directly above larval rearing tanks was maintained between 0 and $532.7 \mu \mathrm{mol}$ $\mathrm{s}^{-1} \mathrm{~m}^{-2}$ (Dataflow Systems Pty Ltd. light logger) (Braley et al., 2018; Militz et al., 2019). The rearing water was maintained between 28.3 and $29.5^{\circ} \mathrm{C}$ with a salinity of 33 ppt.

\section{Spat Nursing}

Most larvae attached and developed secondary shells, feet, gills and symbiotic systems, reaching the juvenile stage at day 15 (Figure 10). Larvae settled within 7 days, and newly settled spat were nursed in the buckets for another 10 weeks with gentle aeration and water flow and 50\% natural lighting. At day 90, 3600 spat from each group (A3, B1, C1, D1, E1) were divided equally between 120 substrates (coral stone, $\sim 16-18 \mathrm{~cm}$ diameter), for a density of 30 individuals/substrate. When the shell length of these spat reached $8-10 \mathrm{~mm}$, they were transferred to an 
TABLE 1 | Analysis of variance (ANOVA) showing giant clam species (CS) and zooxanthellae clade (ZC) effects on survival and growth of each experimental group at different time points.

\begin{tabular}{|c|c|c|c|c|c|c|c|c|}
\hline \multirow[t]{2}{*}{ Items } & \multirow[t]{2}{*}{ Source } & \multirow[t]{2}{*}{$d f$} & \multicolumn{3}{|c|}{ Survival ability } & \multicolumn{3}{|c|}{ Shell length } \\
\hline & & & MS & $F$ value & $P$ & MS & $F$ value & $P$ \\
\hline Implantation & CS & 1 & 0.062 & 6.686 & $0.012^{*}$ & - & - & - \\
\hline \multirow[t]{2}{*}{ rate } & ZC & 4 & 0.143 & 15.356 & $<0.001^{\star \star \star}$ & - & - & - \\
\hline & $\mathrm{C} \times \mathrm{ZC}$ & 4 & 0.004 & 0.421 & 0.793 & - & - & - \\
\hline Metamorphic & CS & 1 & 0.055 & 23.453 & $<0.001^{\star \star \star}$ & - & - & - \\
\hline \multirow[t]{2}{*}{ rate } & $\mathrm{ZC}$ & 4 & 0.034 & 14.569 & $<0.001^{\star \star \star}$ & - & - & - \\
\hline & $C \times Z C$ & 4 & $<0.001$ & 0.128 & 0.972 & - & - & - \\
\hline \multirow[t]{3}{*}{ Day 30} & CS & 1 & - & - & - & 2.238 & 355.436 & $<0.001^{\star \star \star}$ \\
\hline & ZC & 4 & - & - & - & 0.061 & 9.729 & $<0.001^{\star \star \star}$ \\
\hline & $\mathrm{C} \times \mathrm{ZC}$ & 4 & - & - & - & 0.013 & 2.000 & 0.095 \\
\hline \multirow[t]{3}{*}{ Day 90} & $\mathrm{CS}$ & 1 & - & - & - & 0.686 & 147.922 & $<0.001^{\star \star \star}$ \\
\hline & ZC & 4 & - & - & - & 0.101 & 21.689 & $<0.001^{\star \star \star}$ \\
\hline & $\mathrm{C} \times \mathrm{ZC}$ & 4 & - & - & - & 0.001 & 0.227 & 0.923 \\
\hline \multirow[t]{3}{*}{ Day 360} & CS & 1 & $<0.001$ & 0.019 & 0.892 & 7.228 & 0.002 & $<0.001^{\star \star \star}$ \\
\hline & ZC & 4 & 0.005 & 0.656 & 0.624 & 0.102 & 27.466 & $<0.001^{\star \star \star}$ \\
\hline & $C \times Z C$ & 4 & 0.003 & 0.387 & 0.818 & 0.004 & 1.162 & 0.328 \\
\hline
\end{tabular}

*indicates $P<0.05$; **indicates $P<0.01 ;{ }^{* \star *}$ indicates $P<0.001$; df, degrees of freedom; MS, Mean Squares.

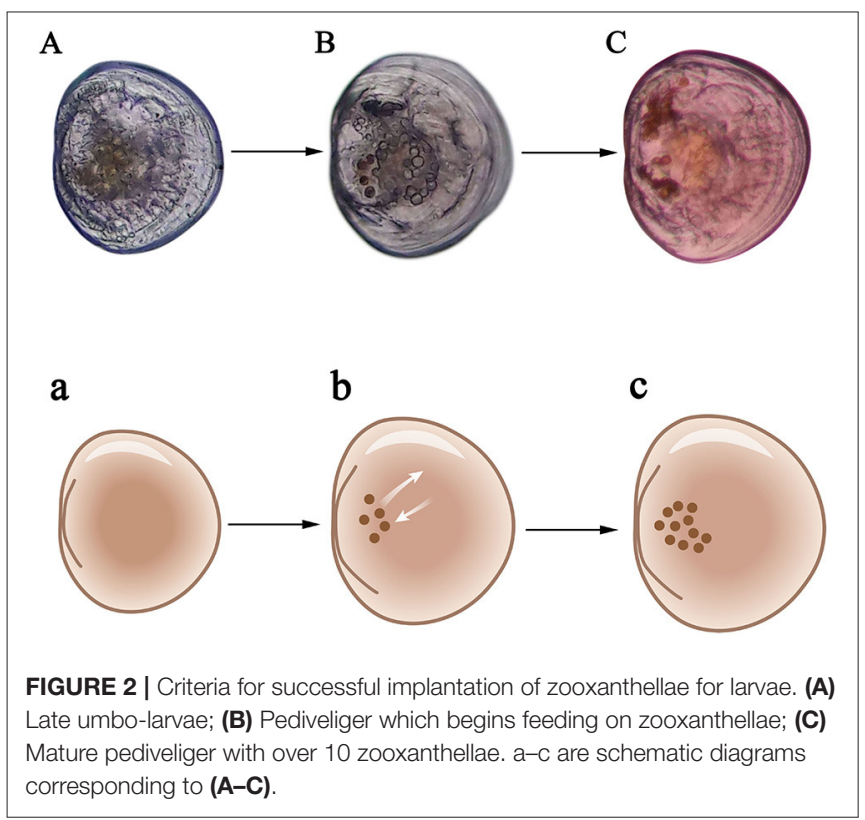

artificial runway system with continuously circulating water. The substrates were cleaned monthly to remove filamentous algae. As the spat grew, the density was reduced from 30 individuals/substrate to 15 individuals/substrate by removing randomly selected spat. Moreover, the dead clams were discarded at every substrate cleaning, and the density of each group was readjusted to maintain similar levels among the groups. Thus, spat were nursed until they were 1 year old (Figures 1P-R). The rearing water was maintained at $25.4-30.0^{\circ} \mathrm{C}$ with a salinity of 33 ppt.

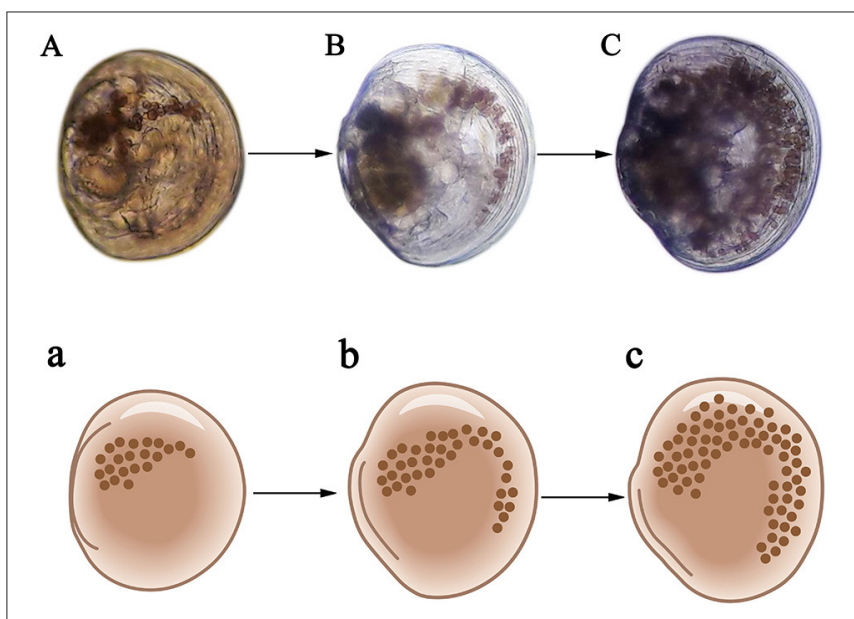

FIGURE 3 | Newly-formed spat with gills, feet, secondary shells, and zooxanthellal tubular systems. (A) Spat with over 30 zooxanthellae; (B) Spat with over 100 zooxanthellae; (C) Spat with over 300 zooxanthellae. a-c are schematic diagrams corresponding to (A-C).

\section{Measurement Index}

The implantation rate was defined as the proportion of larvae with zooxanthellae that were fixed in the stomach and able to proliferate (Figures 2A-C). The metamorphic rate was defined as the proportion of larvae that reached over $250 \mu \mathrm{m}$ in shell length; developed feet, secondary shells and gills; and had zooxanthellae migrate from the digestive tract to the primordial zooxanthellal tubular system, forming a visible line of symbiont cells (Figures 3A-C). Time to metamorphosis was defined as the length of time between fertilization and the point at which over $90 \%$ of larvae had developed into spat. Size at metamorphosis was 


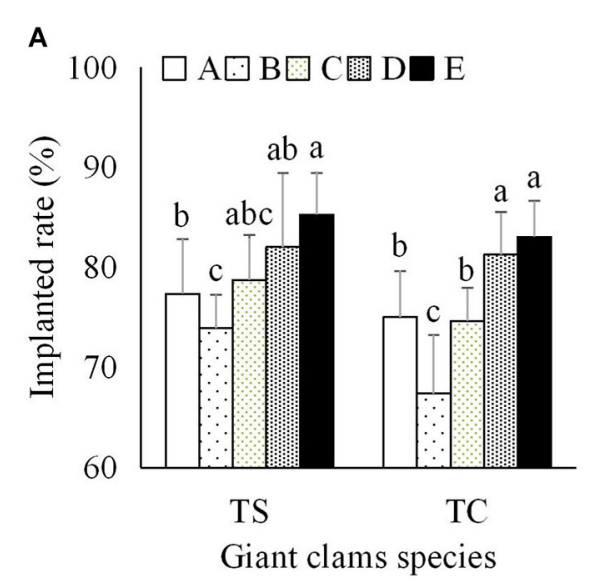

C

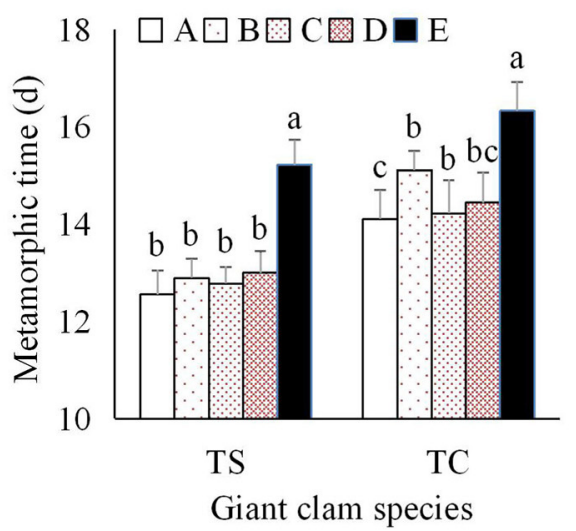

\section{B}

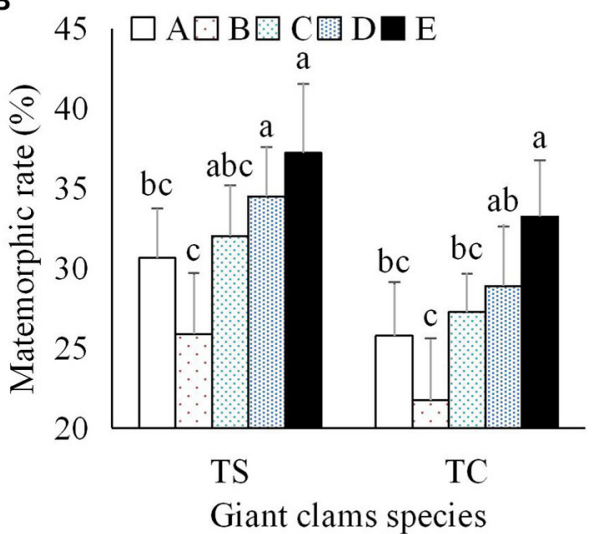

D

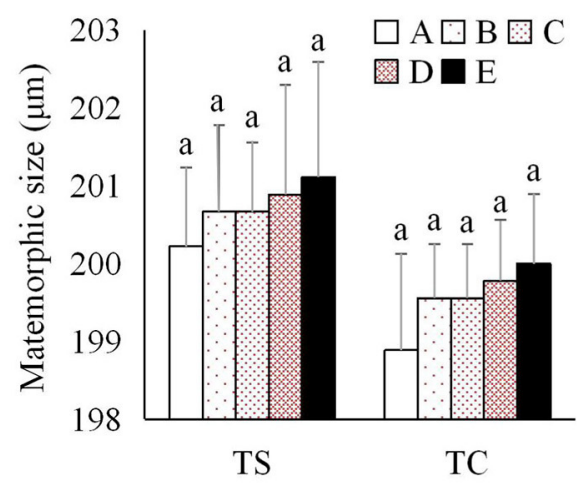

Giant clams species

FIGURE 4 | Effects of zooxanthellae clades A-E on metamorphosis indices of T. squamosa and T. crocea progeny. (A) Implantation rate of zooxanthellae; (B) Metamorphic rate; (C) Time to metamorphosis; (D) Size at metamorphosis.

defined as the maximum shell length reached by the primary shell before metamorphosis.

Shell length was measured using a light microscope when the individual shell length was $<3 \mathrm{~mm}$, and using electronic Vernier calipers (accurate to $0.01 \mathrm{~mm}$ ) when the shell length was over $3 \mathrm{~mm}$. Survival rate to day 360 was defined as the ratio of the number of individuals at juvenile stages to the number of spat (Zhou et al., 2020). The spat size at iridocyte appearance was defined as the shell length when iridocytes were able to be seen using a postural anatomical mirror when $<30$ iridocytes were present. The time to iridocyte appearance was defined as the length of time between fertilization and the point at which over $90 \%$ of spat had iridocytes. The mantle color of the clams at day 360 was divided into two types, BGY (brown, green, and yellow) and bule.

\section{Data Analysis}

Differences in mean implantation rate, metamorphic rate, time to metamorphosis, size at metamorphosis, survival rate, and shell length between groups and replicates were analyzed using multiple comparisons using a two-way ANOVA. To improve the normality and homoscedasticity, the survival ability index was arcsine-transformed prior to analysis, and growth parameters were logarithmically transformed (base 10). All statistical analyses were performed using SPSS 23.0. $P<0.05$ was considered statistically significant for all experiments, unless noted otherwise.

To determine the effects of the clam species and zooxanthella clades on the metamorphosis, survival and growth, a two-factor ANOVA was used (Wang et al., 2011; Wang and Côté, 2012; Zhang et al., 2020a,b), as follows:

$$
\mathrm{Y}_{\mathrm{ijk}}=\mu+\mathrm{CS}_{\mathrm{i}}+\mathrm{ZC}_{\mathrm{j}}+(\mathrm{CS} \times \mathrm{ZC})_{\mathrm{ij}}+\mathrm{e}_{\mathrm{ijk}} .
$$

Here, $\mathrm{Y}_{\mathrm{ijk}}$ is the mean shell length, metamorphosis or survival rate of the $\mathrm{k}$ replicate from the $\mathrm{i}$ clam species ( $T$. squamosa, $T$. crocea) and the $\mathrm{j}$ zooxanthella clade $(\mathrm{A} 3, \mathrm{~B} 1, \mathrm{C} 1, \mathrm{D} 1, \mathrm{E} 1) . \mathrm{CS}_{\mathrm{i}}$ is the effect of clam species on the shell length, metamorphosis or survival rate $(I=1,2) . \mathrm{ZC}_{\mathrm{j}}$ is the effect of zooxanthella clade on the shell length, metamorphosis or survival rate $(j=1,2,3,4,5)$. $(\mathrm{CS} \times \mathrm{ZC})_{\mathrm{ij}}$ is the effect of the interaction between clam species and zooxanthella clade, and $\mathrm{e}_{\mathrm{ijk}}$ is the random observation error $(k=1,2,3)$. 


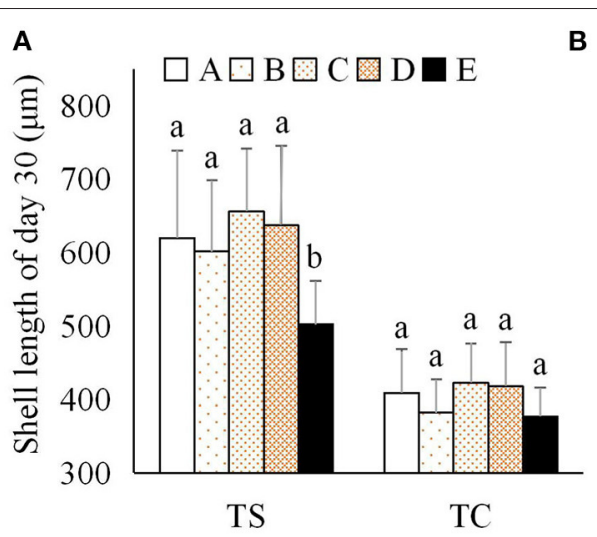

Giant clam species

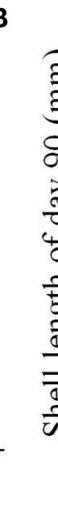

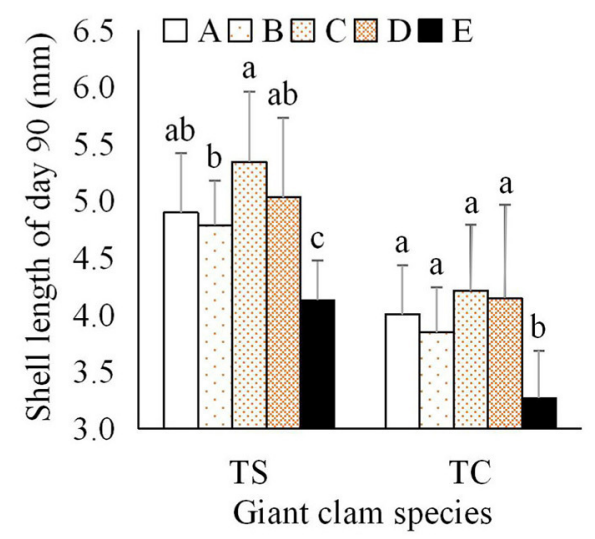

C

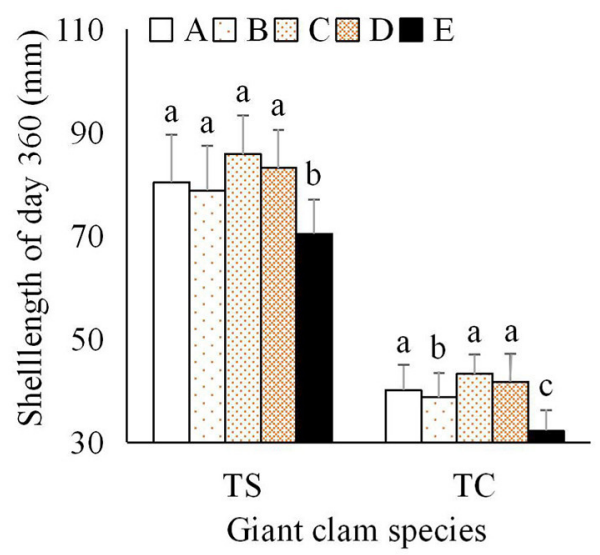

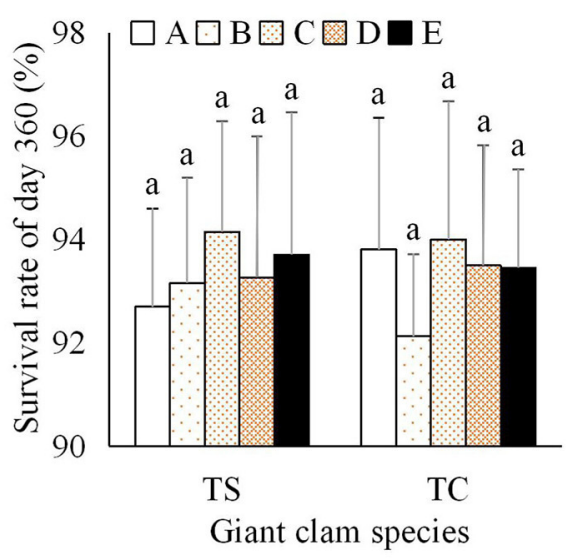

FIGURE 5 | Effects of zooxanthellae clades A-E on growth and survival indices of T. squamosa and T. crocea progeny. (A) Shell length at day 30 ; (B) Shell length at day 90; (C) Shell length at day 360; (D) Survival rate at day 360.

\section{RESULTS}

\section{Metamorphosis}

\section{Implantation Rate}

When giant clam larvae developed to the late-veliger stage (Figure 2A), they were soaked in zooxanthellae solution at a density of $10^{3} / \mathrm{mL}$ for $2 \mathrm{~h}$ daily from day 6 to day 9 . Implantation was considered successful if zooxanthellae were fixed in the stomach and able to proliferate (Figure 2C). Zooxanthellae in clade E1 had the highest implantation rate (Figure 4A). Between the two giant clam species, similar implantation rates were observed for the different zooxanthellae species, and the overall implantation rate of T. squamosa was slightly higher than that of T. crocea. Zooxanthella clade was the primary factor influencing the implantation rate, while the second factor was giant clam species (Table 1).

\section{Metamorphic Rate}

During metamorphosis, zooxanthellae migrate from the digestive tract to primordial zooxanthallal tubular system, forming a visible "line" of symbiont cells. Soon afterward, the siphonal
TABLE 2 | Size at iridocyte appearance and time to iridocyte appearance in progeny of two giant clam species, T. squamosa and T. crocea.

\begin{tabular}{lcccccc}
\hline Zooxanthellae & \multicolumn{2}{c}{$\begin{array}{c}\text { Size at iridocyte } \\
\text { appearance }(\mathbf{m m})\end{array}$} & & \multicolumn{2}{c}{$\begin{array}{c}\text { Time to iridocyte } \\
\text { appearance }(\mathbf{d})\end{array}$} \\
\cline { 2 - 3 } & T. squamosa & T. crocea & & T. squamosa & T. crocea \\
\hline Clade A3 & $1.03 \pm 0.02^{\mathrm{a}}$ & $0.98 \pm 0.02^{\mathrm{a}}$ & & $45.35 \pm 1.49^{\mathrm{a}}$ & $52.33 \pm 1.45^{\mathrm{a}}$ \\
Clade B1 & $1.04 \pm 0.03^{\mathrm{a}}$ & $0.97 \pm 0.03^{\mathrm{a}}$ & & $47.25 \pm 1.52^{\mathrm{a}}$ & $53.50 \pm 1.50^{\mathrm{a}}$ \\
Clade C1 & $1.05 \pm 0.04^{\mathrm{a}}$ & $1.00 \pm 0.02^{\mathrm{a}}$ & & $44.33 \pm 1.50^{\mathrm{a}}$ & $54.67 \pm 1.39^{\mathrm{a}}$ \\
Clade D1 & $1.03 \pm 0.03^{\mathrm{a}}$ & $0.99 \pm 0.03^{\mathrm{a}}$ & & $46.67 \pm 1.35^{\mathrm{a}}$ & $51.39 \pm 1.63^{\mathrm{a}}$ \\
Clade E1 & $1.04 \pm 0.03^{\mathrm{a}}$ & $1.00 \pm 0.03^{\mathrm{a}}$ & & $51.75 \pm 2.16^{\mathrm{b}}$ & $62.75 \pm 2.38^{\mathrm{b}}$
\end{tabular}

Different superscript letters in each column indicate significant differences, $P<0.05$.

mantle and zooxanthellal tubular system were fully formed, and contain hundreds of both dividing and non-dividing zooxanthellae (Figure 3). The metamorphic rate for both species of giant clam was significantly higher with clade E1 than clade A3, C1, and D1, while the metamorphic rate of clams with clade B1 zooxanthellae was significantly lower than that 


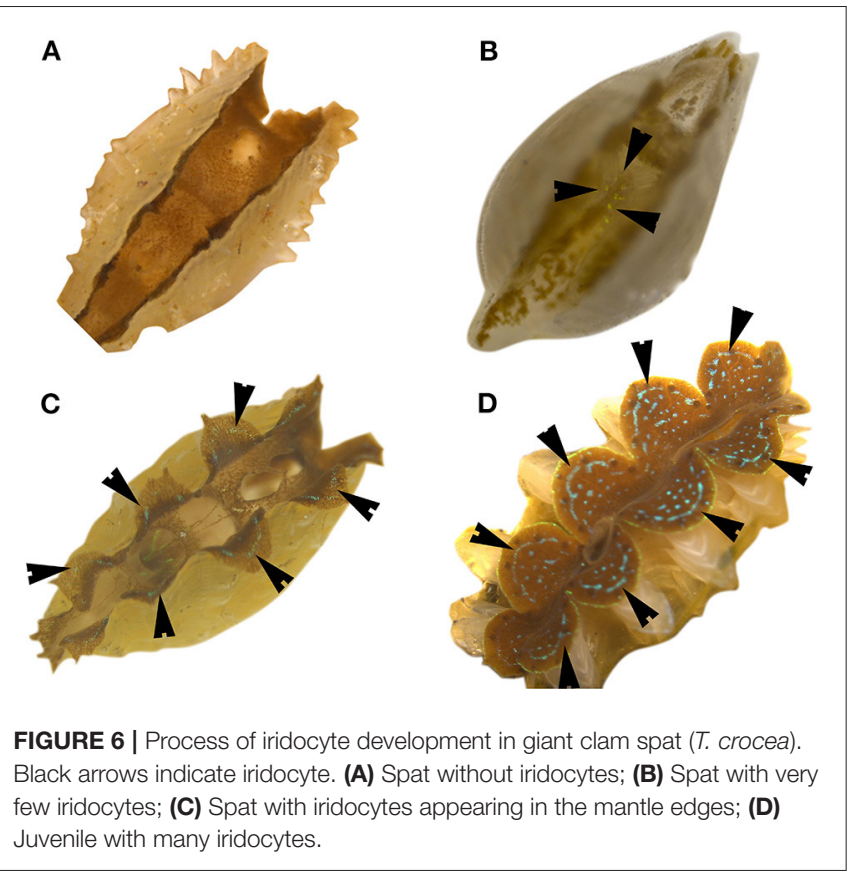

TABLE 3 | Proportion of mantle color patterns in youth of two giant clam species, T. squamosa and T. corcea, at day 360 .

\begin{tabular}{lcccccc}
\hline \multirow{2}{*}{ Zooxanthellae } & \multicolumn{2}{c}{ T. squamosa } & & \multicolumn{2}{c}{ T. crocea } \\
\cline { 2 - 3 } \cline { 6 - 7 } & Kelly & Blue & & Kelly & Blue \\
\hline Clade A3 & $100 \%$ & - & & - & $100 \%$ \\
Clade B1 & $100 \%$ & - & & - & $100 \%$ \\
Clade C1 & $100 \%$ & - & & - & $100 \%$ \\
Clade D1 & $100 \%$ & - & & - & $100 \%$ \\
Clade E1 & $100 \%$ & - & & - & $100 \%$ \\
\hline
\end{tabular}

of progeny with clade C1-E1 zooxanthellae (Figure 4B). The average metamorphic rate of $T$. squamosa was higher than that of $T$. crocea. Metamorphic rate was affected by both zooxanthella clade and giant clam species (Table 1).

\section{Time to Metamorphosis and Size at Metamorphosis}

Time to metamorphosis ranged from 12.56 to $15.22 \mathrm{~d}$ for $T$. squamosa, and from 14.11 to $16.33 \mathrm{~d}$ for T. crocea. Progeny with clade E1 zooxanthellae were significantly delayed during the metamorphic stage compared to those with clades A3, B1D1 (Table 1; Figure 4C). Average size at metamorphosis was $200.71 \mu \mathrm{m}$ for T. squamosa, and $199.56 \mu \mathrm{m}$ for T. crocea. There were no significant differences in size at metamorphosis based on zooxanthella clade or giant clam species (Figure 4D).

\section{Progeny Performance \\ Growth}

At day 30, the mean shell length of $T$. squamosa progeny with clade E1 zooxanthellae was significantly smaller than the other T. squamosa progeny, while T. crocea progeny with clade

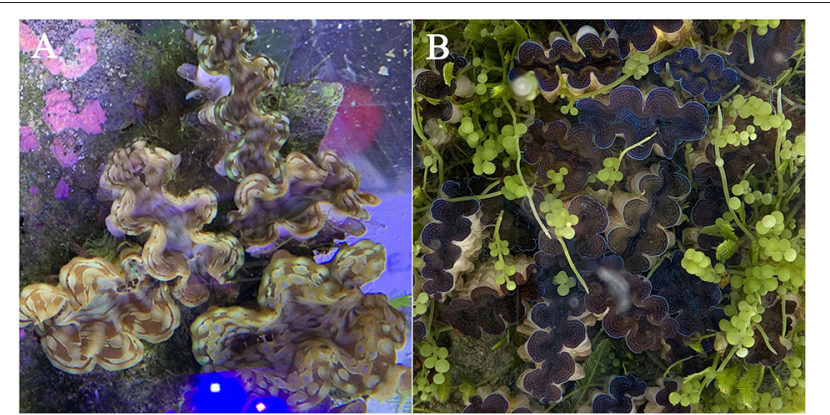

FIGURE 7 | Mantle color patterns of giant clam youth at day 360. (A) indicates BGY color of $T$. squamosa mantles with zooxanthellae in clades A-E; (B) indicates bule color of $T$. crocea mantles with zooxanthellae in clades A-E.

C1 zooxanthellae were significantly larger than progeny with clade E1 (Figure 5A). At day 90, the mean shell length of the progeny of both giant clam species with clade E1 zooxanthellae was significantly smaller than that of the other progeny, and the progeny with clade $\mathrm{C} 1$ zooxanthellae were the largest for both clam species (Figure 5B). At day 360, shell length of progeny ranged from 74.43 to $85.38 \mathrm{~mm}$ for T. squamosa, and from 32.30 to $43.30 \mathrm{~mm}$ for T. crocea. This demonstrates the presence of considerable interspecific differences in growth (Table 1). The progeny with clade $\mathrm{C} 1$ and clade $\mathrm{E} 1$ zooxanthellae were the largest and smallest, respectively, for both giant clam species. In particular, progeny with clade E1 zooxanthellae were significantly smaller than the other progeny, suggesting that zooxanthella phylotype has a significant impact on growth (Table 1; Figure 5C).

\section{Survival}

The survival rate after metamorphosis (shell length $\geq 250 \mu \mathrm{m}$ ) was $100 \%$. Because the mortality of all progeny was very low, we only examined the survival rate at day 360 . The survival rate of T. squamosa progeny with clade A3, B1, C1, D1, and E1 zooxanthellae was 92.70, 93.16, 94.14, 93.27, and 93.70\%, respectively. The survival of $T$. crocea progeny with clade A1, B1, C1, D1, and E1 zooxanthellae was 93.81, 92.13, 94.00, 93.50, and $93.45 \%$, respectively (Figure 5D). The survival rates of all progeny were over $90 \%$, and no significant differences were found between the two giant clam species or five zooxanthella clades using two-factor analysis (Table 1).

\section{Mantle Coloration}

The mantle color of giant clams results from structural color, which is caused by extremely fine structures of iridocytes that reflect certain light rays and eliminate other light rays. Iridocyte formation is a necessary stage in the development of mantle coloration, and is a significant milestone for giant clams. The spat size at iridocyte appearance was about $1 \mathrm{~mm}$ shell length for both giant clams, and there was no significant difference between zooxanthella clades (Table 2). However, the time to iridocyte appearance was $45.35,47.25,44.33,46.67$, and $51.75 \mathrm{~d}$ for $T$. squamosa with clade A3, B1, C1, D1, and E1 zooxanthellae, respectively. The time to iridocyte appearance was $52.33,53.50$, 
54.67, 51.39, and $62.75 \mathrm{~d}$ for $T$. crocea with clade A3, B1, C1, D1, and E1 zooxanthellae, respectively. The time to iridocyte appearance of both clam species was delayed in progeny with clade E1 zooxanthellae. Also, the time to iridocyte appearance was shorter for $T$. squamosa than $T$. crocea (Table 2). In spat of both giant clam species, iridocytes initially formed on the cardioprotective membrane and increased in number as the spat increased in size. Iridocytes then appeared in the mantle, resulting in coloration (Figures 6A-D). Interestingly, at day 360 $100 \%$ of T. squamosa mantles were BGY-colored and 100\% of T. crocea mantles were blue (Table 3; Figures 7A,B).

\section{DISCUSSION}

\section{Metamorphosis}

Metamorphosis is known as a bridge in the life history of marine invertebrates which is of milestone significance (Yan et al., 2009). Unlike most bivalves, giant clams (tridacnines) must establish the zooxanthellal tubular system with Symbiodinium between the late-veliger larvae and spat stages during the metamorphosis process (Mies, 2019). Zooxanthellae isolated from giant clams, corals, and anemones have different effects on larval survival, but all promote the metamorphosis of larvae to giant clam juveniles (Kurihara et al., 2012). However, the effects of various individual zooxanthella species on giant clam metamorphosis remain unclear. Our results show that all zooxanthellae clades A-E were successfully implanted in the stomachs of larvae and caused formation of the zooxanthellal tubular system, allowing the larvae to complete metamorphosis and form spat.

Therefore, in this study, zooxanthellae of clades A-E were identified and ingested by giant clam larvae, and proliferated and produced nutrients in the stomach. Scholars have found that zooxanthellae can produce symbiosis-related fatty acids as a nutrition source for larval metamorphosis (Mies et al., 2017a). Within days after metamorphosis from veliger to a juvenile clam, the zooxanthellal tubules, in which zooxanthellae are packed, elongate from the stomach toward the mantle (Hirose et al., 2006). Zooxanthellae in the tube appear in a line, and we considered the appearance of the line of zooxanthellae in the mantle of juvenile clams to be the first sign of the establishment of symbiosis. The zooxanthellal tubular system developed as the clams grew, particularly in the mantle margin, and then hypertrophied siphonal tissue formed (Hirose et al., 2006). In this study, the metamorphic rate and time to metamorphosis of clams with each clade of zooxanthellae varied. Because each zooxanthellae species may exhibit unique physiological characteristics, the cladal composition may influence the host's survival and development (LaJeunesse et al., 2018).

\section{Growth Divergence}

After metamorphosis, giant clam progeny and Symbiodinium successfully established photosymbiotic relationships, and the zooxanthellae as primary producers would then have provided most nutrition for the juvenile clams (Mies, 2019). Several reports have pointed out that different zooxanthella clades can affect the growth traits of progeny (Kinzie and Chee, 1979; Fitt et al., 1986; Molea and Munro, 1994). For example, Fitt (1985) and Molea and Munro (1994) found that different strains of zooxanthellae grew at different rates inside the host and that fast growing strains resulted in faster growth rates of the clams. Fitt et al. (1986) found that freshly-isolated zooxanthellae conferred higher growth than cultured zooxanthellae when given to veliger in the laboratory.

However, previous studies had not determined whether individual Symbiodinium species affect growth performance. Our results showed that zooxanthella clade affected the growth of giant clam progeny, and interspecific differences were observed between T. squamosa and T. crocea. That is, a single zooxanthella species can affect clam progeny growth traits, which may be caused by differences in physiological characteristics (i.e., ability to adapt to temperature changes) between Symbiodinium species. However, giant clam species had a larger influence on progeny growth than zooxanthella clade in this study. In the wild, both clam species and growth-related characteristics can influence the zooxanthella strains present in giant clams (Ikeda et al., 2017).

\section{Mantle Coloration}

Color polymorphism has been implicated as an important component of cryptic coloration in organisms inhabiting complex environments. Previous studies have suggested that mantle color variations in Tridacnid clams were caused by the composition and distribution of zooxanthellae and may serve a range of functions (Ozog, 2009). However, we found that zooxanthellae in the mantles of giant clams produced only background color by pigment secretion, and expressed mainly brown colors. More importantly, a layer of iridescent cells called iridocytes serve to distribute photosynthetically productive wavelengths by lateral and forward-scattering of light into the tissue while back-reflecting non-productive wavelengths with a Bragg mirror (Holt et al., 2014). Thus, four colors of iridocytes (red, yellow, green, and blue) are produced, and can form various other colors according to the RGB principle (Ghoshal et al., 2016). Moreover, mantle color in giant clams has little to no correlation to different geographical populations or gene flows (Benzie, 1993; Benzie and Williams, 1995, 1997, 1998).

Whether individual zooxanthella species can affect mantle coloration is unclear. In this study, clams with all zooxanthella species had normal mantle color expression, with zooxanthella species affecting time to iridocyte appearance but not spat size at iridocyte appearance. Interestingly, the early iridocytes were all green, with other colors (blue or others) appearing as the clams grew. That is, green is the starting color for iridocytes, and may be the lead color during iridocyte development. Furthermore, structural color expression of giant clam progeny can only be seen with the naked eye when iridocytes reach a certain number and density. Without sufficient iridocytes, the mantle simply appears brown.

\section{CONCLUSION}

Zooxanthellae in clades A-E can promote larval metamorphosis, with some variation in metamorphic rate between clades. 
All these zooxanthella species were able to supply nutrition through photosynthesis, but produced differences in clam growth between experimental groups. Growth characteristics of each group of progeny were most affected by variation between clam species, and secondarily affected by zooxanthella species. Survival rates of all groups of progeny were over $90 \%$, with no significant effect of zooxanthella species on survival. There was no relationship between mantle color and zooxanthella species, and mantle colors were determined by iridocytes according to the RGB principle. This study provides useful information for seed production and aquaculture of giant clams.

\section{DATA AVAILABILITY STATEMENT}

The original contributions presented in the study are included in the article/supplementary material, further inquiries can be directed to the corresponding authors.

\section{ETHICS STATEMENT}

Giant clam parents were collected with the approval of the Hainan provincial government (China) and with minimal impacts on the local ecological environment. Written informed consent was obtained from the owners for the participation of their animals in this study.

\section{AUTHOR CONTRIBUTIONS}

YZha and JL designed this experiments. ZY, CL, YL, and JL carried out this experiments. ZZ, YQ, XL, HM, and JW collected data. YZho and ZN analysised data. ZY and CL wrote this

\section{REFERENCES}

Belda-Baillie, C. A., Sison, M., Silvestre, V., Villamor, K., Monje, V., Gomez, E. D., et al. (1999). Evidence for changing symbiotic algae in juvenile tridacnids. J. Exp. Mar. Biol. Ecol. 241, 207-221. doi: 10.1016/S0022-0981(99)00079-9

Benzie, J. A. H. (1993). "Review of the population genetics of giant clams $[\mathrm{C}] / /$ Genetic aspects of conservation and cultivation of giant clams," in ICLARM Conference Proceedings (Makati), 1-6.

Benzie, J. A. H., and Williams, S. T. (1995). Gene flow among giant clam (Tridacna gigas) populations in Pacific does not parallel ocean circulation. Mar. Biol. 123:781. doi: 10.1007/BF00349121

Benzie, J. A. H., and Williams, S. T. (1997). Genetic structure of giant clam (Tridacna maxima) populations in the West Pacific is not consistent with dispersal by present-day ocean currents. Evolution 51, 768-783. doi: 10.1111/j.1558-5646.1997.tb03660.x

Benzie, J. A. H., and Williams, S. T. (1998). Phylogenetic relationships among giant clam species (Mollusca: Tridacnidae) determined by protein electrophoresis. Mar. Biol. 132, 123-133. doi: 10.1007/s002270050378

bin Othman, A. S., Goh, G. H., and Todd, P. A. (2010). The distribution and status of giant clams (family Tridacnidae)-a short review. Raffles Bull. Zool. 58, 103-111.

Braley, R. D., Militz, T. A., and Southgate, P. C. (2018). Comparison of three hatchery culture methods for the giant clam Tridacna noae. Aquaculture 495, 881-887. doi: 10.1016/j.aquaculture.2018.05.044

Fitt, W. K. (1985). "Effect of different strains of the zooxanthellae Symbiodinium microadriaticum on growth and survival of their coelenterate and paper. All authors contributed to the article and approved the submitted version.

\section{FUNDING}

This work was supported by the National Science Foundation of China (31872566 and 31702340); Key Special Project for Introduced Talents Team of Southern Marine Science and Engineering Guangdong Laboratory (Guangzhou) (GML2019ZD0404); the Network Service Local Plan STS of the Chinese Academy of Sciences (KFJ-STS-QYZD-158); the Chinese Ministry of Science and Technology through the National Key Research and Development Program of China (2018YFC1406505, 2018YFD0901400, and 2020YFD0901102); the Strategic Priority Research Program of the Chinese Academy of Sciences (XDA13020202, XDA13020203, and XDA13020403); Guangzhou City programs, Guangdong province, China (201803020047 and 201804020073); the Innovation Academy of South China Sea Ecology and Environmental Engineering, Chinese Academy of Sciences (ISEE2018PY01, ISEE2018ZD02, and ISEE2018PY03); the Open Foundation of the State Key Laboratory of Loess and Quaternary Geology (SKLLQG1813 and SKLLQG1918); the China Agricultural Shellfish Industry Technology System Project (CARS-49); and the Science and Technology Planning Project of Guangdong Province, China (2017B030314052).

\section{ACKNOWLEDGMENTS}

The authors would like to thank the editor, three reviewers, Dr. Victoria L. Pruente and Xuekai Zhang for their assistance in the manuscript revision process. molluscan hosts," in Proceedings of the 5th International Coral Reef Congress (Tahiti), 131-136.

Fitt, W. K., Fisher, C. R., and Trench, R. K. (1986). Contribution of the symbiotc dinoflagellate Symbiodinium microadriaticum to the nutrition, growth, and survial of larval and juvenile tridacnid clams. Aquaculture 55, 5-22. doi: 10.1016/0044-8486(86)90051-7

Ghoshal, A., Eck, E., and Morse, D. E. (2016). Biological analogs of RGB pixelation yield white coloration in giant clams. Optica 3, 108-111. doi: 10.1364/OPTICA.3.000108

Hernawan, U. E. (2008). Symbiosis between the giant clams (Bivalvia: Cardiidae) and zooxanthellae (Dinophyceae). Biodivers. J. Biol. Divers. 9, 53-58. doi: 10.13057/biodiv/d090113

Hirose, E., Iwai, K., and Maruyama, T. (2006). Establishment of the photosymbiosis in the early ontogeny of three giant clams. Mar. Biol. 148, 551-558. doi: 10.1007/s00227-005-0119-x

Holt, A. L., Vahidinia, S., Gagnon, Y. L., Morse, D. E., and Sweeney, A. M. (2014). Photosymbiotic giant clams are transformers of solar flux. J. R. Soc. Interface 11:20140678. doi: 10.1098/rsif.2014.0678

Huang, H., Dong, Z., Huang, L., and Li, Y. (2008). Reagent Case for Extracting Zooxanthellae Genom from Ledge Rock Coral and Method Thereof. China Invention Patent, Authorization No., ZL200810027305.6. State Intellectual Property Office of the People's Republic of China, Beijing, China.

Ikeda, S., Yamashita, H., Kondo, S. N., Inoue, K., Morishima, S. Y., and Koike, K. (2017). Zooxanthellal genetic varieties in giant clams are partially determined by species-intrinsic and growth-related characteristics. PLOS ONE 12:e0172285. doi: 10.1371/journal.pone.0172285 
Kinzie, I. I. I. R. A., and Chee, and, G. S. (1979). The effect of different zooxanthellae on the growth of experimentally reinfected hosts. Biol. Bull. 156, 315-327. doi: $10.2307 / 1540920$

Kirkendale, L., and Paulay, G. (2017). Treatise Online no. 89: Part N, Revised, Volume 1, Chapter 9: Photosymbiosis in Bivalvia. Lawrence, KS: Treatise Online.

Kurihara, T., Yamashita, H., Yamada, H., Inoue, K., Iwai, K., and Koike, K. (2012). Probability of symbiosis establishment by giant clams with fresh and cultured Symbiodinium isolated from various host animals. J. Shellfish. Res. 31, 977-988. doi: $10.2983 / 035.031 .0410$

LaJeunesse, T. C., Parkinson, J. E., Gabrielson, P. W., Jeong, H. J., Reimer, J. D., Voolstra, C. R., et al. (2018). Systematic revision of Symbiodiniaceae highlights the antiquity and diversity of coral endosymbionts. Curr. Biol. 28, 2570-2580. doi: 10.1016/j.cub.2018.07.008

Mies, M. (2019). Evolution, diversity, distribution, and the endangered future of the giant clam-Symbiodiniaceae association. Coral Reef 38, 1067-1084. doi: 10.1007/s00338-019-01857-x

Mies, M., Chaves-Filho, A. B., Miyamoto, S., Güth, A. Z., Tenório, A. A., Castro, C. B., et al. (2017a). Production of three symbiosis-related fatty acids by Symbiodinium types in clades A-F associated with marine invertebrate larvae. Coral Reefs 36, 1319-1328. doi: 10.1007/s00338-017-1627-0

Mies, M., Güth, A. Z., Castro, C. B., Pires, D. O., Calderon, E. N., Pompeu, M., et al. (2018). Bleaching in reef invertebrate larvae associated with Symbiodinium strains within clades A-F. Mar. Biol. 165:6. doi: 10.1007/s00227-0173263-1

Mies, M., Voolstra, C. R., Castro, C. B., Pires, D. O., Calderon, E. N., and Sumida, P. Y. G. (2017b). Expression of a symbiosis-specific gene in Symbiodinium type A1 associated with coral, nudibranch, and giant clam larvae. R. Soc. Open. Sci. 4:170253. doi: $10.1098 /$ rsos. 170253

Militz, T. A., Braley, R. D., Schoeman, D. S., and Southgate, P. C. (2019). Larval and early juvenile culture of two giant clam (Tridacninae) hybrids. Aquaculture 500, 500-505. doi: 10.1016/j.aquaculture.2018.10.050

Molea, T., and Munro, P. E. (1994). Influence of symbiont strain on early growth of tridacnids. Asian Fish. Sci. 7, 91-102.

Morishima, S. Y., Yamashita, H., and Shizuka, O. (2019). Study on expelled but viable zooxanthellae from giant clams, with an emphasis on their potential as subsequent symbiont sources. PLOS ONE 14:e0220141. doi: 10.1371/journal.pone.0220141

Neo, M. L., Eckman, W., Vicentuan, K., Teo, S. L. M., and Todd, P. A. (2015). The ecological significance of giant clams in coral reef ecosystems. Biol. Conserv. 181, 111-123. doi: 10.1016/j.biocon.2014.11.004

Neo, M. L., Wabnitz, C. C., Braley, R. D., Heslinga, G. A., Fauvelot, C., Van Wynsberge, S., et al. (2017). Giant clams (Bivalvia: Cardiidae: Tridacninae): a comprehensive update of species and their distribution, current threats, and conservation status. Oceanogr. Mar. Biol. 55, 87-388. doi: 10.1201/b2 1944-5
Ozog, S. T. (2009). Balancing Anti-Predation and Energetic Needs: Color Polymorphism in the Giant Clam Tridacna maxima. Berkeley, CA: University of California.

Rossbach, S., Subedi, R. C., Ng, T. K., Ooi, B. S., and Duarte, C. M. (2020). Iridocytes mediate photonic cooperation between giant clams (Tridacninae) and their photosynthetic symbionts. Front. Mar. Sci. 7:465. doi: $10.3389 /$ fmars.2020.00465

Wang, C., and Côté, J. (2012). Heterosis and combining abilities in growth and survival in sea scallops along the Atlantic coast of Canada. J. Shellfish Res. 31, 1145-1149. doi: 10.2983/035.031.0425

Wang, C., Liu, B., Li, J., Liu, S., Li, J., Hu, L., et al. (2011). Introduction of the Peruvian scallop and its hybridization with the bay scallop in China. Aquaculture 310, 380-387. doi: 10.1016/j.aquaculture.2010.11.014

Yan, X., Zhang, Y., Huo, Z., Yang, F., and Zhang, G. (2009). Effects of starvation on larval growth, survival, and metamorphosis of Manila clam Ruditapes philippinarum. Acta Ecol. Sin. 29, 327-334. doi: 10.1016/j.chnaes.2009.09.012

Yu, Z., Zhang, Y., Xiao, S., and Ma, H. (2016). Method for Acquiring Zooxanthellae. China Invention Patent, Authorization No.: ZL201610454183.3.

Zhang, Y., Ma, H., Li, X., Zhou, Z., Li, J., Wei, J., et al. (2020b). Analysis of inbreeding depression on performance traits of three giant clams (Tridacna derasa, T. squamosa, and T. crocea) in the South China Sea. Aquaculture 521:735023. doi: 10.1016/j.aquaculture.2020.735023

Zhang, Y., Xiao, S., Li, J., Ma, H., Xiang, Z., Zhang, Y., et al. (2016). The artificial breeding and early development of the fluted giant clam (Tridacna squamosa) in South China Sea. J. Fish. China 40, 1713-1723. doi: 10.11964/jfc.20160610459

Zhang, Y., Zhou, Z., Qin, Y., Li, X., Ma, H., Wei, J., et al. (2020a). Phenotypic traits of two boring giant clam (Tridacna crocea) populations and their reciprocal hybrids in the South China Sea. Aquaculture 519:734890. doi: 10.1016/j.aquaculture.2019.734890

Zhou, Z., Li,. J., Ma, H., Qin, Y., Zhou, Y., Wei, J., et al. (2020). Artificial interspecific hybridization of two giant clams, Tridacna squamosa, and Tridacna crocea, in the South China Sea. Aquaculture 515:734581. doi: 10.1016/j.aquaculture.2019.734581

Conflict of Interest: The authors declare that the research was conducted in the absence of any commercial or financial relationships that could be construed as a potential conflict of interest.

Copyright (c) 2021 Long, Zhang, Li, Li, Zhou, Qin, Li, Ma, Wei, Zhou, Noor, Long and $Y u$. This is an open-access article distributed under the terms of the Creative Commons Attribution License (CC BY). The use, distribution or reproduction in other forums is permitted, provided the original author(s) and the copyright owner(s) are credited and that the original publication in this journal is cited, in accordance with accepted academic practice. No use, distribution or reproduction is permitted which does not comply with these terms. 